\title{
The absolute and relative change of high-sensitivity cardiac troponin I are associated with in-hospital outcome of patients with fulminant myocarditis
}

\section{Chao Liu}

Division of Cardiology, Department of Internal Medicine, and Hubei Key Laboratory of Genetics and Molecular Mechanisms of Cardiological Disorders, Tongji Hospital, Tongji Medical College, Huazhong Uni Zhongqin Wang

Division of Cardiology, Department of Internal Medicine, and Hubei Key Laboratory of Genetics and Molecular Mechanisms of Cardiological Disorders, Tongji Hospital, Tongji Medical College, Huazhong Uni

\section{Kengquan Chen}

Division of Cardiology, Department of Internal Medicine, and Hubei Key Laboratory of Genetics and Molecular Mechanisms of Cardiological Disorders, Tongji Hospital, Tongji Medical College, Huazhong Uni

\section{Guanglin Cui}

Division of Cardiology, Department of Internal Medicine, and Hubei Key Laboratory of Genetics and Molecular Mechanisms of Cardiological Disorders, Tongji Hospital, Tongji Medical College, Huazhong Uni Chen chen

Division of Cardiology, Department of Internal Medicine, and Hubei Key Laboratory of Genetics and Molecular Mechanisms of Cardiological Disorders, Tongji Hospital, Tongji Medical College, Huazhong Uni

\section{Luyun Wang}

Division of Cardiology, Department of Internal Medicine, and Hubei Key Laboratory of Genetics and Molecular Mechanisms of Cardiological Disorders, Tongji Hospital, Tongji Medical College, Huazhong Uni Jiangang Jiang ( $\square$ jiangjg618@126.com )

Division of Cardiology, Department of Internal Medicine, and Hubei Key Laboratory of Genetics and Molecular Mechanisms of Cardiological Disorders, Tongji Hospital, Tongji Medical College, Huazhong Uni

\section{Research Article}

Keywords: fulminant myocarditis, high-sensitivity troponin I, absolute change, relative change, in-hospital outcome

Posted Date: January 8th, 2021

DOI: https://doi.org/10.21203/rs.3.rs-133930/v1 
License: (c) (i) This work is licensed under a Creative Commons Attribution 4.0 International License. Read Full License 


\section{Abstract \\ Background}

we sought to describe the tendency and extent of high-sensitivity cardiac troponin I (hs-cTnl) changes in patients with fulminant myocarditis (FM) after admission, and to explore the relationship between inhospital outcome of FM and the value of absolute and relative change of hs-cTnl within $24 \mathrm{~h}$ and $48 \mathrm{~h}$ after admission.

\section{Methods}

a total of 83 cases of FM patient admitted to our center from January 1, 2010 to December 31, 2019 were included, 69 patients survived and 14 patients died. The absolute and relative change of hs-cTnl within $24 \mathrm{~h}$ and $48 \mathrm{~h}$ were described as range distribution. Receiver operating characteristic (ROC) curves and Cox analysis were performed to determine the relationship between in-hospital outcome of FM and hscTnl change.

\section{Results}

In survive group, $78 \%$ patients experienced the decline of hs-cTnl within $24 \mathrm{~h}$, while $36 \%$ of death group had the declined tendency of hs-cTnl $(P=0.003)$. Absolute and relative change of hs-cTnl within $24 \mathrm{~h}$ and $48 \mathrm{~h}$ were displayed as range distribution. Multivariate analysis revealed that the decline tendency of hscTnl change within $24 \mathrm{~h}$, in addition with time from onset to hospital, intravenous immunoglobulin treatment and abnormal of creatinine, were associated with the outcome of FM (for the decline tendency of hs-cTnl within $24 \mathrm{~h}, \mathrm{OR}=0.10,95 \% \mathrm{Cl}=0.02-0.68, P=0.018$ ). ROC curve revealed optimized cutoff values of $-0.618 \mathrm{ng} / \mathrm{ml}$ for absolute change within $24 \mathrm{~h}(\mathrm{AUC}=0.800, P<0.01),-4.389 \mathrm{ng} / \mathrm{ml}$ for absolute change within $48 \mathrm{~h}$ (Area Under Curve $=0.711, P<0.01$ ), $-28.46 \%$ for relative change within $24 \mathrm{~h}$ (AUC = $0.810, P<0.01),-52.23 \%$ for relative change within $48 \mathrm{~h}(\mathrm{AUC}=0.795, P<0.01)$. Absolute change and relative change of hs-cTnl within $24 \mathrm{~h}$ and $48 \mathrm{~h}$ were strong predictors of in-hospital mortality by COX regression analyzed, after the adjustment for gender, time from onset to admission, occurrence of ventricular tachycardia or ventricular fibrillation.

\section{Conclusion}

Most survive FM patients experienced the decline of hs-cTnl within $24 \mathrm{~h}$. The absolute and relative change of hs-cTnl within $24 \mathrm{~h}$ and $48 \mathrm{~h}$ were strong predictors of in-hospital mortality.

\section{Introduction}


Myocarditis is an inflammatory disease of the myocardium which has a broad spectrum of clinical presentations, ranging from mild symptoms to life-threatening arrhythmias and/or severe heart failure $(\mathrm{HF})^{1}$. Fulminant myocarditis (FM) is a rare but the most severe type of myocarditis and is characterized by sudden occurrence, rapid progress, and hemodynamic dysfunction ${ }^{2}$. Though endomyocardial biopsy $(E M B)$ is the golden standard of myocarditis diagnosis, it is pragmatic to determine the treatment for the patients suspected of myocarditis by clinical diagnosis referred to clinical state as well as laboratory and imaging tests ${ }^{2,3}$. To be exactly, FM can be clinically defined as patients presenting with a distinct onset of symptoms in the prior 2 weeks, severe symptoms of HF, and hypotension or overt cardiogenic shock needing inotropes, vasopressor, and/or mechanical circulation support ${ }^{3}$. As the technology advanced, gadolinium contrast-enhanced cardiac magnetic resonance (CMR) can afford tissue-level pathologies consistent with myocarditis, including myocardial edema and fibrosis (e.g., T2- and T1-weighted sequences and late gadolinium enhancement [LGE]) which has high diagnostic accuracy ${ }^{4,5}$.

Myocarditis is an inflammatory cardiac disorder induced predominantly by viruses ${ }^{6}$. The mechanisms of myocardial injury were recognized as the direct injury and the indirect immunogenic injury ${ }^{7}$. The former indicates the intracellular viral replication in the myocardium and other tissues, resulting in degeneration, necrosis, and dysfunction ${ }^{8}$. The latter is triggered by cytotoxic and antigen-antibody reaction which are caused by virus infection ${ }^{9}$. An elevated serum cardiac troponin (cTn) is almost always observed in patients with FM as myocardial injury, especially the assay of high-sensitivity troponin I (hs-cTnl) detection was more sensitive in reflecting the potential injury of myocardium. The same as hs-cTnl elevated, research in patients with myocardial infraction (MI) about the diagnostic and prognostic value of serial changes of hs-cTnl had been widely performed ${ }^{10-15}$. It is undetermined that the FM patients' hscTnl kinetic in the early phase after admission and the relationship between the serial change of hs-cTnl and patients' outcome.

Therefore, this retrospective research aimed to describe the serial changes of hs-cTnl, and to determine the prognostic value of the absolute $(\Delta)$ and relative $(\Delta \%)$ changes in hs-cTnl within $24 \mathrm{~h}$ and $48 \mathrm{~h}$ after admission for FM patients' outcome in hospital.

\section{Method}

\subsection{Study population and diagnosis of fulminant myocarditis}

All patients were in-hospital patients in TongJi hospital, a tertiary teaching medical center in Wuhan, China. From January 1, 2010 to December 31, 2019. A total of 105 FM cases were retrospectively included in the study, of whom 22 cases were excluded (Fig. 1). The exclusive criteria include: 1) age less than 16 years old, 2) diagnosis of other severe disease, such as malignant tumor. 3) dead within $24 \mathrm{~h}$ after admission to hospital, 4) lack of serial hs-cTnl record within $48 \mathrm{~h}$. At last, the final analysis consist of 83 FM patients. 
FM is usually defined as myocardial inflammatory disease with a rapid outbreak complicated with severe hemodynamic dysfunction. FM is more likely to be a clinical diagnosis rather than a histological or pathological diagnosis. Therefore, FM was diagnosed in our center, predominantly as Chinese expert consensus statement recommended ${ }^{2}$, by following signs: sudden attack, obvious premonitory symptoms of viral infection (especially severe fatigue and poor appetite), and rapid emerging severe hemodynamic dysfunction, serious myocardial injuries, and diffuse ventricular wall motion decrease. Since 2018, CMR was widely used in our center to ascertain the diagnosis of FM, 25 cases of $36 \mathrm{FM}$ patients in that period performed CMR examination. EMB had been performed in 3 patients with unexplained heart failure as the guideline recommended ${ }^{16}$. Coronary angiography had been operated in 36 cases to distinguish from myocardial infraction for clinical signs as chest pain and elevated ST wave in electrocardiogram and elevated hs-cTnl ${ }^{17}$. All patients' ultimate diagnosis was ascertained by at least two cardiologists before admitted to the study.

\subsection{Data collection and hs-cTnl detection}

All patients at admission underwent clinical assessments including clinical history, physical examination, 12-lead electrocardiogram, echocardiography, and standard blood tests. Patients' outcome in hospital were recorded. All hs-cTnl value measured after admission within 7 days were recorded to describe the kinetic of hs-cTnl which was test by ARCHITECT i2000SR (Abbott Laboratories). The serial change of hs-

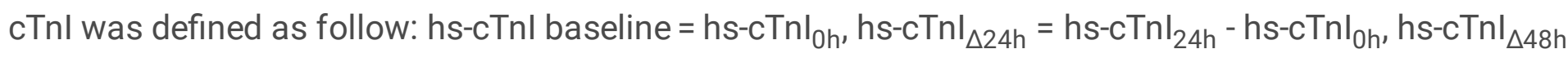

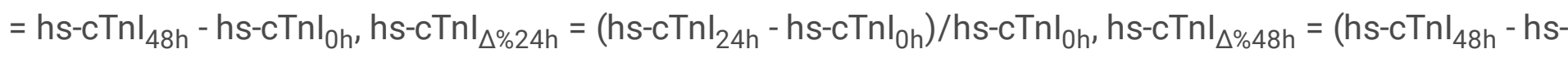
$\left.\mathrm{cTnI}_{\mathrm{Oh}}\right) / \mathrm{hs}-\mathrm{cTnI} \mathrm{Oh}_{\mathrm{h}}$.

\subsection{Statistical analysis}

The data are presented as proportions, mean $\pm S D$, and median with interquartile range if variable was nonnormal distribution. Comparisons were made with the $t$ test for normally distributed continuous variables, Mann-Whitney $\mathrm{U}$ test for nonnormally distributed continuous variables, $\chi 2$ test for categorical variables. Receiver operating characteristic (ROC) curves were constructed to assess the relationship between in-hospital outcome of FM and the value of absolute $(\Delta)$ and relative $(\Delta \%)$ changes of hs-cTnl within 24 hour and 48 hours after admission. Optimal cutoff values were derived from ROC curves as described by Youden, and sensitivity, specificity, were calculated. Cox regression analysis was performed to determine the prognostic value of optimal cutoff of absolute $(\Delta)$ and relative $(\Delta \%)$ changes of hs-cTnl within 24 hour and 48 hours. All hypothesis testing was 2 tailed, and a P value of 0.05 was considered statistically significant. All statistical analyses were performed with SPSS 22.0 (SPSS Inc., Chicago, IL) for Windows (Microsoft Corp, Redmond, WA).

\section{Result}

\section{1 characteristics of FM patients}


The baseline characteristics of all 83 FM patients are shown in Table 1. The median age was 37 (Q1-Q3: 29-48) years old, $49.4 \%$ were women. Premonitory symptoms of viral infection, like fever, was observed in $75.9 \%$ of total population while the co-existing conditions including hypertension or diabetes mellitus were observed in less than $10 \%$ of patients. The median time from onset to admission was 3 days, which indicated that FM was an acute disease; while this period in survive group was significant shorter than in death group $(P=0.028)$. Chest distress $(69.9 \%)$ was the most common symptoms of FM patients, and chest pain $(22.9 \%)$, palpitation $(22.9 \%)$, dizziness $(25.3 \%)$, and disturbances of consciousness $(21.7 \%)$ were also recorded. The incidence of severe arrhythmia, such as ventricular tachycardia or ventricular fibrillation, was significant higher in death group than in survive group ( $35.7 \%$ vs. $10.1 \%, P=0.026)$. Higher level of creatinine rather than alanine transaminase was also observed at admission in death group than survive group ( $P=0.016) .42 \%$ of survive group received CMR examination, all of the examination were performed in the recent two years, while no patients in death group received such examination as severe hemodynamic dysfunction. Coronary angiography was performed in $28.6 \%$ of death group and $46.4 \%$ of survive group. Patients in death group with so rapid illness progression as to all of them received vasoactive agent( $100 \%), 50 \%$ of whom received intraaortic balloons pump(IABP) and mechanical ventilation therapy. The majority of patients (87\%) in survive group were performed IABP to maintain hemodynamic stable. Vasoactive agent was used in $66.7 \%$ of survive patients and mechanical ventilation was used in $36.2 \%$ of survive patients. About $20 \%$ of patients in both group operated extracorporeal membrane oxygenation (ECMO). 
Table 1

Baseline characteristics of FM

\begin{tabular}{|c|c|c|c|c|}
\hline & $\begin{array}{l}\text { total }(n= \\
83)\end{array}$ & death $(n=14)$ & $\begin{array}{l}\text { survive(n } \\
=69)\end{array}$ & $P$ \\
\hline Female n;(\%) & $41(49.4)$ & $6(42.9)$ & $35(50.7)$ & 0.591 \\
\hline age (year) & $37[29,48]$ & $42.5[32.75,50.75]$ & $37[27,47.5]$ & 0.226 \\
\hline \multicolumn{5}{|l|}{ Median[Q1-Q3] } \\
\hline $\begin{array}{l}\text { Premonitory symptoms of viral infection n; } \\
(\%)\end{array}$ & $63(75.9)$ & 10(71.4) & $53(76.8)$ & 0.735 \\
\hline \multicolumn{5}{|l|}{ Co-existing conditions n;(\%) } \\
\hline Hypertension & $6(7.2)$ & $1(7.1)$ & $5(7.2)$ & 1.000 \\
\hline Diabetes mellitus & $4(4.8)$ & 0 & $4(5.8)$ & 1.000 \\
\hline Renal disease & $1(1.2)$ & $1(7.1)$ & 0 & 0.169 \\
\hline $\begin{array}{l}\text { Time from onset to admission (days) } \\
\text { Median[Q1-Q3] }\end{array}$ & $3[2,5]$ & $4.5[2.75,10.25]$ & $3[1,4.5]$ & 0.028 \\
\hline Coronary angiography (n, \%) & $36(43.3)$ & $4(28.6)$ & $32(46.4)$ & 0.220 \\
\hline CMR (n,\%) & 29(34.9) & 0 & $29(42.0)$ & 0.002 \\
\hline \multicolumn{5}{|l|}{ Clinical symptoms n ;(\%) } \\
\hline Chest pain & 19(22.9) & $2(14.3)$ & $17(24.6)$ & 0.506 \\
\hline Chest distress & $58(69.9)$ & 10(71.4) & $48(69.6)$ & 1.000 \\
\hline Palpitation & $19(22.9)$ & $3(21.4)$ & 16(23.2) & 1.000 \\
\hline Dizziness & $21(25.3)$ & $2(14.3)$ & 19(27.5) & 0.501 \\
\hline Disturbances of consciousness & 18(21.7) & $3(21.4)$ & 15(21.7) & 1.000 \\
\hline Ejection fraction at lowest $\%$ & $\begin{array}{l}33.7 \pm \\
13.5\end{array}$ & $40.9 \pm 15.3$ & $32.5 \pm 13.0$ & 0.056 \\
\hline \multicolumn{5}{|l|}{ ECG n ;(\%) } \\
\hline ST-segment elevation & $30(36.1)$ & $4(28.6)$ & $26(37.7)$ & 0.518 \\
\hline Ventricular Tachycardia or & $12(14.5)$ & $5(35.7)$ & $7(10.1)$ & 0.026 \\
\hline \multicolumn{5}{|l|}{ Ventricular fibrillation } \\
\hline Atrioventricular block & 14(16.9) & $2(14.3)$ & 12(17.4) & 1.000 \\
\hline $\begin{array}{l}\text { CMR = cardiac magnetic resonance; ECG = } \\
\text { creatinine; IVIG = Intravenous immunoglobu } \\
\text { extracorporeal membrane oxygenation. }\end{array}$ & $\begin{array}{l}\text { trocardioc } \\
\text { IABP = Int }\end{array}$ & $\begin{array}{l}\text {; ALT = Alanine am } \\
\text { ortic balloons pump }\end{array}$ & $\begin{array}{l}\text { lotransferas } \\
\mathrm{ECMO}=\end{array}$ & Crea $=$ \\
\hline
\end{tabular}




\begin{tabular}{|c|c|c|c|c|}
\hline & $\begin{array}{l}\text { total }(n= \\
83)\end{array}$ & death $(n=14)$ & $\begin{array}{l}\text { survive(n } \\
=69)\end{array}$ & $P$ \\
\hline $\operatorname{ALT}(x \pm s)$ & $\begin{array}{l}552 \pm \\
1185\end{array}$ & $1133 \pm 2156$ & $434 \pm 850$ & 0.252 \\
\hline $\operatorname{Crea}(x \pm s)$ & $107 \pm 110$ & $205 \pm 157$ & $87 \pm 86$ & 0.016 \\
\hline Vasoactive agent n;(\%) & $60(72.3)$ & 14(100) & $46(66.7)$ & 0.008 \\
\hline Anti-viral therapy n;(\%) & $81(97.6)$ & 12(85.7) & $69(100)$ & 0.027 \\
\hline Glucocorticoid therapy n;(\%) & $83(100)$ & $14(100)$ & $69(100)$ & 1.000 \\
\hline IVIG n;(\%) & 73(88.0) & $8(57.1)$ & $65(94.2)$ & 0.001 \\
\hline Mechanical ventilation $\mathrm{n} ;(\%)$ & $32(38.6)$ & $7(50.0)$ & $25(36.2)$ & 0.335 \\
\hline IABP n;(\%) & $67(80.7)$ & $7(50.0)$ & $60(87.0)$ & 0.004 \\
\hline ECMO n;(\%) & $19(22.9)$ & $3(21.4)$ & $16(23.2)$ & 1.000 \\
\hline IABP + ECMO n;(\%) & $17(20.5)$ & $3(21.4)$ & $14(20.3)$ & 1.000 \\
\hline
\end{tabular}

\section{2 baseline and tendency of hs-cTnl}

The baseline hs-cTnl was illustrated in Fig. 2A, which revealed no significant difference between the death and survive groups(value: survive patients $27.62 \pm 2.4 \mathrm{ng} / \mathrm{ml}$ and death patients $31.05 \pm 7.1 \mathrm{ng} / \mathrm{ml}, P=$ $0.81)$. hs-cTnl tested within $24 \mathrm{~h}$ lower than hs-cTnl baseline was defined as declined tendency, otherwise it was defined as not declined tendency. Figure 2B showed the significant difference of tendency of hscTnl change in death and survive FM patients within $24 \mathrm{~h}$ after admission, in survive group $78 \%$ patients experienced the declined hs-cTnl change, while $36 \%$ of death group had the declined tendency of hs-cTnl $(P=0.003)$.

\section{3 absolute and relative hs-cTnl changes within $24 \mathrm{~h}$ and $48 \mathrm{~h}$}

As available hs-cTnl data was concentrate within $24 \mathrm{~h}$ and $48 \mathrm{~h}$ after admission, the absolute and relative changes of hs-cTnl in these periods were illustrated in Table 2 and Fig. 3. The absolute change of hs-cTnl in survival group within $24 \mathrm{~h}$ was mainly at the scale of -10 to $0 \mathrm{ng} / \mathrm{ml}$, accounting for $39.68 \%$ of the patients, followed by the scale of -20 to $-10 \mathrm{ng} / \mathrm{ml}$ which accounted for $19.05 \%$ of the patients. The relative change of hs-cTnl within $24 \mathrm{~h}$ was concentrated in $-25 \%$ to $-75 \%$, accounting for $58.07 \%$ of patients. The absolute change of hs-cTnl within $48 \mathrm{~h}$ was concentrate in -10 to $0 \mathrm{ng} / \mathrm{ml}$ incorporating 
$32.3 \%$ patients and in -20 to $-30 \mathrm{ng} / \mathrm{ml}$, accounting for $22.03 \%$. Survive patients with relative change of hs-cTnl within $48 \mathrm{~h}$ between $-50 \%$ to $-100 \%$ account for $72.41 \%$. In death group, the absolute change of hs-cTnl both within $24 \mathrm{~h}$ and $48 \mathrm{~h}$ were concentrated in 0 to $10 \mathrm{ng} / \mathrm{ml}$, which account for $50 \%$ and $37.5 \%$ respectively. Main scale of relative change of hs-cTnl in death group changed from 0 to $25 \%$ within $24 \mathrm{~h}$ to $-50 \%$ to $-75 \%$ within $48 \mathrm{~h}$, accounting for $46.67 \%$ and $25 \%$ of patients respectively. Main scale of hscTnl distribution in the survive group and death group within both $24 \mathrm{~h}$ and $48 \mathrm{~h}$ have significant statistic difference. 
Table 2

Distribution of hs-cTnl change in survive group and death group within $24 \mathrm{~h}$ and $48 \mathrm{~h}$

\begin{tabular}{|c|c|c|c|c|c|c|}
\hline & $\begin{array}{l}\text { Survive group } \\
\text { proportion } \\
\text { with } 24 \mathrm{~h}\end{array}$ & $\begin{array}{l}\text { Death group } \\
\text { proportion } \\
\text { within } 24 \mathrm{~h}\end{array}$ & $P$ & $\begin{array}{l}\text { Survive group } \\
\text { proportion } \\
\text { within } 48 \mathrm{~h}\end{array}$ & $\begin{array}{l}\text { Death group } \\
\text { proportion } \\
\text { within } 48 \mathrm{~h}\end{array}$ & $P$ \\
\hline & $\%(n=63)$ & $\%(n=14)$ & & $\%(n=58)$ & $\%(n=8)$ & \\
\hline \multicolumn{7}{|c|}{ Absolute change of hs-cTnl (ng/ml) } \\
\hline$[-50,-40)$ & 1.59 & 0 & 1.000 & 5.08 & 0 & 1.000 \\
\hline$[-40,-30)$ & 4.76 & 0 & 1.000 & 10.17 & 12.50 & 1.000 \\
\hline$[-30,-20)$ & 14.29 & 0 & 0.198 & 22.03 & 0 & 0.338 \\
\hline$[-20,-10)$ & 19.05 & 14.29 & 1.000 & 18.64 & 12.50 & 1.000 \\
\hline$[-10,0)$ & 39.68 & 14.29 & 0.120 & 32.20 & 25.00 & 1.000 \\
\hline$[0,10)$ & 15.87 & 50.00 & $0.011^{*}$ & 5.08 & 37.50 & $0.019^{*}$ \\
\hline$[10,20)$ & 3.17 & 14.29 & 0.149 & 3.39 & 12.50 & 0.321 \\
\hline$[20,30)$ & 1.59 & 0 & 1.000 & 1.69 & 0 & 1.000 \\
\hline$[30,40)$ & 0 & 7.14 & 0.182 & 1.69 & 0 & 1.000 \\
\hline \multicolumn{7}{|c|}{ Relative change of hs-cTnl (*100\%) } \\
\hline$[-1,-0.75)$ & 11.29 & 0 & 0.334 & 31.03 & 0 & 0.095 \\
\hline$[-0.75,-0.5)$ & 30.65 & 6.67 & 0.098 & 41.38 & 25.00 & 0.464 \\
\hline$[-0.5,-0.25)$ & 27.42 & 6.67 & 0.170 & 10.34 & 12.50 & 1.000 \\
\hline$[-0.25,0)$ & 11.29 & 13.33 & 1.000 & 6.90 & 12.50 & 0.487 \\
\hline$[0,0.25)$ & 9.68 & 46.67 & $0.002^{*}$ & 1.72 & 25.00 & $0.037^{*}$ \\
\hline$[0.25,0.5)$ & 1.61 & 6.67 & 0.354 & 0 & 0 & - \\
\hline$[0.5,0.75)$ & 1.61 & 0 & 1.000 & 1.72 & 0 & 1.000 \\
\hline$[0.75,1)$ & 1.61 & 0 & 1.000 & 0 & 12.50 & 0.121 \\
\hline$[1,2)$ & 4.84 & 20.00 & 0.084 & 6.90 & 12.50 & 0.487 \\
\hline
\end{tabular}

\subsection{Univariate analysis and multivariate analysis for outcome of FM}


Univariate analysis was operated to select factors potentially associated with the outcome of FM, and the result was displayed in Table 3. There are 6 variables showing statistical significance, including the time from onset to hospital, occurrence of ventricular Tachycardia or ventricular fibrillation, abnormal of creatinine, the decline tendency of hs-cTnl change within $24 \mathrm{~h}$, Intravenous immunoglobulin (IVIG) treatment and operation of IABP. Those variables were taken into multivariate analysis. The results showed that the decline tendency of hs-cTnl change within $24 \mathrm{~h}$, in addition with the abnormal of creatinine, IVIG treatment and time from onset to hospital were associate with the outcome of FM (for time from onset to hospital, $\mathrm{OR}=1.3,95 \% \mathrm{Cl}=1.02-1.75, P=0.04$; for abnormal of creatinine, $\mathrm{OR}=7.85$, $95 \% \mathrm{Cl}=1.19-51.74, P=0.032$; for the decline tendency of hs-cTnl change within $24 \mathrm{~h}, \mathrm{OR}=0.10,95 \% \mathrm{Cl}$ $=0.02-0.68, P=0.018$; for IVIG treatment, $\mathrm{OR}=0.028,95 \% \mathrm{Cl}=0.003-0.3, P=0.003$ ). 
Table 3

Univariate analysis and multivariate analysis for outcome of FM.

\begin{tabular}{|c|c|c|c|c|}
\hline \multirow[t]{2}{*}{ Factor } & \multicolumn{2}{|l|}{ Univariate analysis } & \multicolumn{2}{|c|}{ Multivariate analysis } \\
\hline & $\mathrm{OR}(95 \% \mathrm{Cl})$ & $P$ & $\mathrm{OR}(95 \% \mathrm{Cl})$ & $P$ \\
\hline Female & $0.73(0.23-2.32)$ & 0.592 & & \\
\hline age (year) & $1.02(0.98-1.07)$ & 0.321 & & \\
\hline Premonitory symptoms of viral infection & $1.33(0.37-4.80)$ & 0.668 & & \\
\hline Time from onset to admission & $1.22(1.03-1.45)$ & 0.023 & $1.34(1.02-1.75)$ & 0.038 \\
\hline Chest pain & $1.96(0.40-9.66)$ & 0.407 & & \\
\hline Chest distress & $0.91(0.26-3.25)$ & 0.890 & & \\
\hline Disturbances of consciousness & $1.02(0.25-4.12)$ & 0.979 & & \\
\hline \multicolumn{5}{|l|}{ Ejection fraction at lowest \% } \\
\hline ST-segment elevation & $0.66(0.19-2.33)$ & 0.520 & & \\
\hline Ventricular Tachycardia or & $4.92(1.28-18.86)$ & 0.020 & $6.68(0.87-51.04)$ & 0.067 \\
\hline \multicolumn{5}{|l|}{ Ventricular fibrillation } \\
\hline Atrioventricular block & $0.79(0.16-4.00)$ & 0.778 & & \\
\hline ALT & $1.33(0.38-4.70)$ & 0.655 & & \\
\hline Crea & $9.82(2.68-36.02)$ & 0.001 & $7.85(1.19-51.74)$ & 0.032 \\
\hline IVIG & $0.08(0.02-0.35)$ & 0.001 & $0.03(0.003-0.3)$ & 0.003 \\
\hline Mechanical ventilation & $1.76(0.55-5.60)$ & 0.338 & & \\
\hline IABP & $0.150(0.04-0.53)$ & 0.003 & - & - \\
\hline ECMO & $0.90(0.22-3.64)$ & 0.886 & & \\
\hline $\mathrm{IABP}+\mathrm{ECMO}$ & $1.07(0.26-4.37)$ & 0.923 & & \\
\hline Tendency of hs-cTnl within $24 \mathrm{~h}$ & $0.09(0.02-0.32)$ & $<0.01$ & $0.1(0.02-0.68)$ & 0.018 \\
\hline
\end{tabular}

\subsection{Value of absolute hs-cTnl change and relative hs-cTnl change in predicting hospital mortality}


ROC curve was performed to calculate cutoff and to evaluate the value of absolute and relative hs-cTnl change in predicting in-hospital outcome of FM. Results including cutoff, area under curve(AUC), $95 \%$ confidence interval were displayed as Fig. 4 and Table 4, showing that the predictable value of absolute hs-cTnl changes for hospital mortality of FM was high both within $24 \mathrm{~h}$ (cutoff $=-0.618 \mathrm{ng} / \mathrm{ml}$; AUC, 0.80; $95 \%$ confidence interval, 0.692 to 0.883 ) and within $48 \mathrm{~h}$ (cutoff $=-4.389 \mathrm{ng} / \mathrm{ml} ; \mathrm{AUC}, 0.711 ; 95 \%$ confidence interval, 0.587 to 0.816 ). The accuracy of relative hs-cTnl change for predicting FM mortality in hospital also high both within $24 \mathrm{~h}$ (cutoff $=-28.46 \% ; A U C, 0.81 ; 95 \%$ confidence interval, 0.704 to 0.891 ) and within $48 \mathrm{~h}$ (cutoff=-52.23\%;AUC, $0.795 ; 95 \%$ confidence interval, 0.678 to 0.885 ). There was no significant difference among the relative change and absolute change at both time points $(P>0.05$ for comparison; Fig. 4 and Table 3). Cox regression analysis for mortality in FM patients grouped by cutoff of relative and absolute change of hs-cTnl within $24 \mathrm{~h}$ and $48 \mathrm{~h}$ were shown in Fig. 5 and Table 5. The factors that absolute change of hs-cTnl and relative change of hs-cTnl within both $24 \mathrm{~h}$ and $48 \mathrm{~h}$ in addition with elevated creatinine were strong predictors of in-hospital mortality, after adjustment for gender, time from onset to admission, occurrence of ventricular tachycardia and ventricular fibrillation (hs-cTnl $_{\Delta 24 \mathrm{~h}}>-0.618 \mathrm{ng} / \mathrm{ml}: \mathrm{HR}=6.93[1.88-25.64], P=0.004 ; \mathrm{hs}^{-\mathrm{cTnl}} \mathrm{L}_{\triangle 8 \mathrm{~h}}>-4.389 \mathrm{ng} / \mathrm{ml}: \mathrm{HR}=6.47$ [1.29-32.42], $P=0.023$; hs-cTnI ${ }_{\Delta \% 24 \mathrm{~h}}>-28.46 \%: \mathrm{HR}=13.83$ [1.76-108.95], $P=0.013$; hs-cTnI $_{\Delta \% 48 \mathrm{~h}}>$ $-52.23 \%: \mathrm{HR}=19.88$ [2.40-164.79], $P=0.006)$.

Table 4

Diagnostic value of hs-cTnl $\Delta 24 \mathrm{~h}$, hs-cTnl $\Delta 48 \mathrm{~h}$, hs-cTnl $\Delta \% 24 \mathrm{~h}$, hs-cTnl $\Delta \% 48 \mathrm{~h}$ for hospital mortality of patients with fulminant myocarditis.

\begin{tabular}{|llllll|}
\hline & AUC & $\boldsymbol{P}$ & Cutoff & sensitivity & specificity \\
\hline hs-cTnl $_{\triangle 24 \mathrm{~h}}$ & 0.800 & $<0.01$ & -0.618 & 78.57 & 79.03 \\
\hline hs-cTnl $_{\triangle 48 \mathrm{~h}}$ & 0.711 & $<0.01$ & -4.389 & 75.00 & 72.41 \\
\hline hs-cTnl $_{\triangle \% 24 \mathrm{~h}}$ & 0.810 & $<0.01$ & -0.2846 & 92.86 & 67.74 \\
\hline hs-cTnl $_{\triangle \% 48 \mathrm{~h}}$ & 0.795 & $<0.01$ & -0.5223 & 87.50 & 70.69 \\
\hline
\end{tabular}


Table 5

Cox proportional hazards analysis for death in FM.

\begin{tabular}{|c|c|c|c|}
\hline & HR & $95 \% \mathrm{Cl}$ & P-Value \\
\hline \multicolumn{4}{|l|}{ Model 1} \\
\hline $\mathrm{hs}-\mathrm{cTnI}_{\Delta 24 \mathrm{~h}}>-0.618 \mathrm{ng} / \mathrm{ml}$ & 6.93 & $1.88-25.64$ & 0.004 \\
\hline Elevated creatinine & 4.63 & $1.41-15.19$ & 0.011 \\
\hline \multicolumn{4}{|l|}{ Model 2} \\
\hline hs-cTnl ${ }_{\triangle 48 h}>-4.389 \mathrm{ng} / \mathrm{ml}$ & 6.47 & $1.29-32.42$ & 0.023 \\
\hline Elevated creatinine & 19.03 & $2.32-155.85$ & 0.006 \\
\hline \multicolumn{4}{|l|}{ Model 3} \\
\hline hs-cTnl ${ }_{\Delta \% 24 h}>-28.46 \%$ & 13.83 & $1.76-108.95$ & 0.013 \\
\hline Elevated creatinine & 4.04 & $1.24-13.15$ & 0.020 \\
\hline \multicolumn{4}{|l|}{ Model 4} \\
\hline hs-cTnl $\Delta \% 48 h>-52.23 \%$ & 19.88 & $2.40-164.79$ & 0.006 \\
\hline Elevated creatinine & 27.20 & $3.28-225.40$ & 0.002 \\
\hline
\end{tabular}

\section{Discussion}

The main findings of this study include three aspects: 1) we firstly described the tendency and extent of hs-cTnl change within $24 \mathrm{~h}$ and $48 \mathrm{~h}$ after admission in FM; 2) we determined the tendency of hs-cTnl change within $24 \mathrm{~h}$ was associated with in-hospital outcome of $\mathrm{FM} ; 3$ ) we further determined that the extent of hs-cTnl change as absolute change and relative change within $24 \mathrm{~h}$ and $48 \mathrm{~h}$ were significant factors to predict outcome of FM.

Detection of hs-cTnl at admission is recommended in guidelines regarding myocarditis ${ }^{17,18}$, for almost all patients showed elevated troponin. Enrico Ammirati reported a cohort study comprised 118 myocarditis patients with left ventricular ejection fraction (LVEF) less than $50 \%$ and 325 myocarditis patients with no such complications, above $99 \%$ of whom in both groups have increased troponin at admission ${ }^{19}$. Little research focused on the relationship between the serial change of cardiac troponin and the outcome of myocarditis, the majority of which explored hs-cTnl baseline prognostic value. There were studies demonstrated that the level of cardiac troponin was not associated with the outcome $e^{20-22}$. 
In contrary, other studies reported that elevated troponin in the early phase for myocarditis was associated with ECMO or worse prognosis ${ }^{23,24}$. It is still debated that the prognostic value of cardiac troponin baseline in myocarditis.

Though the increased level of hs-cTnl in FM is well-recognized, it is unknown that the tendency and exact extent of hs-cTnl change in reality. This study described the situation of hs-cTnl change, revealing that it is regular for hs-cTnl change in FM. Most survive patients experienced decline of hs-cTnl change within $24 \mathrm{~h}$ while few patients in death group had decreased hs-cTnl, significantly differently compared to survive group. Within $24 \mathrm{~h}$ after admission, $40 \%$ of survive patients had absolute change of hs-cTnl dropped by $0-10 \mathrm{ng} / \mathrm{ml}$ and $58 \%$ of survive patients showed relative change of hs-cTnl dropped by $25 \%-75 \%$. While patients in death group have absolute change of hs-cTnl increased by $0-10 \mathrm{ng} / \mathrm{ml}$, accounting for $50 \%$. The depiction of hs-cTnl change in FM is of importance for us to know more about fulminant myocarditis and give better treatment for patients.

Besides, the declined tendency of hs-cTnl change within $24 \mathrm{~h}$ was found to be associated with in-hospital outcome of FM, after the adjustment of the abnormal of creatinine, IVIG treatment and time from onset to hospital. The declined tendency may reveal that treatment for FM in our center was effective, including anti-viral therapy, immunomodulating therapy, circulation support, and respiratory support, resulting in the relief of inflammation reaction which caused myocardium injury and reduction of incidence of ventricular tachycardia or ventricular fibrillation. In contrary, the opposite tendency may inflected that inflammation reaction was still severe after treatment, with high incidence of arrhythmia.

Furthermore, the prognostic value of extent of hs-cTnl change, as absolute change and relative change, within $24 \mathrm{~h}$ and $48 \mathrm{~h}$ was explored. The results revealed that the concrete absolute and relative change within $24 \mathrm{~h}$ and $48 \mathrm{~h}$ were associated with in-hospital outcome of FM. Specifically, if FM patients have absolute change of hs-cTnl within $24 \mathrm{~h}$ dropped as to $0.618 \mathrm{ng} / \mathrm{ml}$ or relative change dropped as to $28.46 \%$, it is more likely for them to survive, which can also be predicted by the absolute change of hscTnl within $48 \mathrm{~h}$ dropped as to $4.389 \mathrm{ng} / \mathrm{ml}$ or relative decline change dropped as to $52.23 \%$. This result is beneficial for doctors to evaluate treatment regimen and patients' prognostication. If patients experience declined tendency within $24 \mathrm{~h}$ with the magnitude reached our proposed cutoff value, the outcome may be good. But the patient's hs-cTnl change within $24 \mathrm{~h}$ show increased tendency or the magnitude dropped not reach the cut-off value, it may remind doctor to reassess the treatment for better control of inflammation reaction.

There are still some limitations in the current study. The retrospective nature of this research may have introduced potential bias. Although we collect all FM patients in our singer center for 10 years, the cases are not enough for further subanalysis. The median time for patients from onset to hospital was three days, thus the peak time of hs-cTnl is undetermined for patients experienced declined tendency of hs-cTnl after admission. The prospective research with more regular and frequent detection of hs-cTnl need to be performed for better understanding of hs-cTnl change in FM. 


\section{Conclusion}

Most survive FM patients have decline tendency of hs-cTnl change under treatment within the early phase. The absolute and relative changes of hs-cTnl within $24 \mathrm{~h}$ and $48 \mathrm{~h}$ have significant predictable value for the in-hospital outcome of FM.

\section{Abbreviations}

hs-cTnl: high-sensitivity troponin l; FM: fulminant myocarditis; ROC: Receiver operating characteristic; AUC: area under curve; HF: heart failure; EMB: endomyocardial biopsy; CMR: cardiac magnetic resonance; LGE: late gadolinium enhancement; cTn: cardiac troponin; MI: myocardial infraction; IABP: Intraaortic balloons pump; ECMO: extracorporeal membrane oxygenation; IVIG: Intravenous immunoglobulin; LVEF: left ventricular ejection fraction;

\section{Declarations}

\section{Acknowledgements:}

Not applicable.

\section{Authors' contributions:}

CL: data collection and manuscript writing. ZQW: manuscript writing and data analysis. KQC: data collection and management. GLC: data analysis. LYW: manuscript revision and data review. CC: manuscript revision. JGJ: research design and manuscript revision. All authors have read and approved the manuscript.

\section{Funding:}

None.

\section{Availability of data and materials}

The information and data of the study population were acquired from Hospital Information System and were recorded manually in EXCEL to form the database. The datasets analyzed during the current study are not publicly available due to the protection of the individual privacy but are available from the corresponding author on reasonable request.

\section{Ethics approval and consent to participate}

All methods were performed in accordance with the relevant guidelines and regulations. The study has been approved by the Tongji Hospital, Tongji Medical College, Huazhong University of Science and Technology Institutional Review Board (TJ-C20160202). Informed consent was obtained from all 
participants. The database is not open to public, thus the individual privacy of the participants could be well protected.

\section{Consent for publication}

Not applicable.

\section{Competing interests}

The authors declare that they have no competing interests.

\section{Author details}

1 Division of Cardiology, Department of Internal Medicine, and Hubei Key Laboratory of Genetics and Molecular Mechanisms of Cardiological Disorders, Tongji Hospital, Tongji Medical College, Huazhong University of Science and Technology, Wuhan 430030, China.

\section{References}

1. Ammirati E, Veronese G, Cipriani M, et al. Acute and Fulminant Myocarditis: a Pragmatic Clinical Approach to Diagnosis and Treatment. Current cardiology reports. 2018;20:114.

2. Wang D, Li S, Jiang J, et al. Chinese society of cardiology expert consensus statement on the diagnosis and treatment of adult fulminant myocarditis. Science China Life sciences. 2019;62:187202.

3. Ginsberg F and Parrillo JE. Fulminant myocarditis. Critical care clinics. 2013;29:465-83.

4. Friedrich MG, Sechtem U, Schulz-Menger J, et al. Cardiovascular magnetic resonance in myocarditis: A JACC White Paper. Journal of the American College of Cardiology. 2009;53:1475-87.

5. Lurz P, Eitel I, Adam J, et al. Diagnostic performance of CMR imaging compared with EMB in patients with suspected myocarditis. JACC Cardiovascular imaging. 2012;5:513-24.

6. Dominguez F, Kühl U, Pieske B, et al. Update on Myocarditis and Inflammatory Cardiomyopathy: Reemergence of Endomyocardial Biopsy. Revista espanola de cardiologia (English ed). 2016;69:178-87.

7. Tschöpe C, Ammirati E, Bozkurt B, et al. Myocarditis and inflammatory cardiomyopathy: current evidence and future directions. Nature reviews Cardiology. 2020:1-25.

8. Badorff C, Lee GH, Lamphear BJ, et al. Enteroviral protease 2A cleaves dystrophin: evidence of cytoskeletal disruption in an acquired cardiomyopathy. Nature medicine. 1999;5:320-6.

9. Kühl U, Pauschinger $M$, Noutsias $M$, et al. High prevalence of viral genomes and multiple viral infections in the myocardium of adults with "idiopathic" left ventricular dysfunction. Circulation. 2005;111:887-93.

10. Neumann JT, Twerenbold R, Ojeda F, et al. Application of High-Sensitivity Troponin in Suspected Myocardial Infarction. The New England journal of medicine. 2019;380:2529-2540. 
11. Haaf P, Drexler B, Reichlin T, et al. High-sensitivity cardiac troponin in the distinction of acute myocardial infarction from acute cardiac noncoronary artery disease. Circulation. 2012;126:31-40.

12. Wildi K, Reichlin T, Twerenbold R, et al. Serial changes in high-sensitivity cardiac troponin I in the early diagnosis of acute myocardial infarction. International journal of cardiology. 2013;168:410310.

13. Su Q, Guo Y, Liu H, et al. Diagnostic Role of High-Sensitivity Cardiac Troponin T in Acute Myocardial Infarction and Cardiac Noncoronary Artery Disease. Archives of medical research. 2015;46:193-8.

14. Januzzi JL, Jr., Suchindran S, Hoffmann U, et al. Single-Molecule hs-cTnl and Short-Term Risk in Stable Patients With Chest Pain. Journal of the American College of Cardiology. 2019;73:251-260.

15. Walter J, du Fay de Lavallaz J, Koechlin L, et al. Using High-Sensitivity Cardiac Troponin for the Exclusion of Inducible Myocardial Ischemia in Symptomatic Patients: A Cohort Study. Annals of internal medicine. 2020;172:175-185.

16. Cooper LT, Baughman KL, Feldman AM, et al. The role of endomyocardial biopsy in the management of cardiovascular disease: a scientific statement from the American Heart Association, the American College of Cardiology, and the European Society of Cardiology Endorsed by the Heart Failure Society of America and the Heart Failure Association of the European Society of Cardiology. European heart journal. 2007;28:3076-93.

17. Caforio AL, Pankuweit S, Arbustini E, et al. Current state of knowledge on aetiology, diagnosis, management, and therapy of myocarditis: a position statement of the European Society of Cardiology Working Group on Myocardial and Pericardial Diseases. European heart journal. 2013;34:2636-48, 2648a-2648d.

18. Kociol RD, Cooper LT, Fang JC, et al. Recognition and Initial Management of Fulminant Myocarditis: A Scientific Statement From the American Heart Association. Circulation. 2020;141:e69-e92.

19. Ammirati E, Cipriani M, Moro C, et al. Clinical Presentation and Outcome in a Contemporary Cohort of Patients With Acute Myocarditis: Multicenter Lombardy Registry. Circulation. 2018;138:1088-1099.

20. Kobayashi D, Aggarwal S, Kheiwa A, et al. Myopericarditis in children: elevated troponin I level does not predict outcome. Pediatric cardiology. 2012;33:1040-5.

21. Imazio M, Brucato A, Spodick $\mathrm{DH}$, et al. Prognosis of myopericarditis as determined from previously published reports. Journal of cardiovascular medicine (Hagerstown, Md). 2014;15:835-9.

22. Al-Biltagi M, Issa M, Hagar HA, et al. Circulating cardiac troponins levels and cardiac dysfunction in children with acute and fulminant viral myocarditis. Acta paediatrica (Oslo, Norway. 1992). 2010;99:1510-6.

23. Butto A, Rossano JW, Nandi D, et al. Elevated Troponin in the First $72 \mathrm{~h}$ of Hospitalization for Pediatric Viral Myocarditis is Associated with ECMO: An Analysis of the PHIS + Database. Pediatric cardiology. 2018;39:1139-1143.

24. Miyake CY, Teele SA, Chen L, et al. In-hospital arrhythmia development and outcomes in pediatric patients with acute myocarditis. The American journal of cardiology. 2014;113:535-40. 
Figures

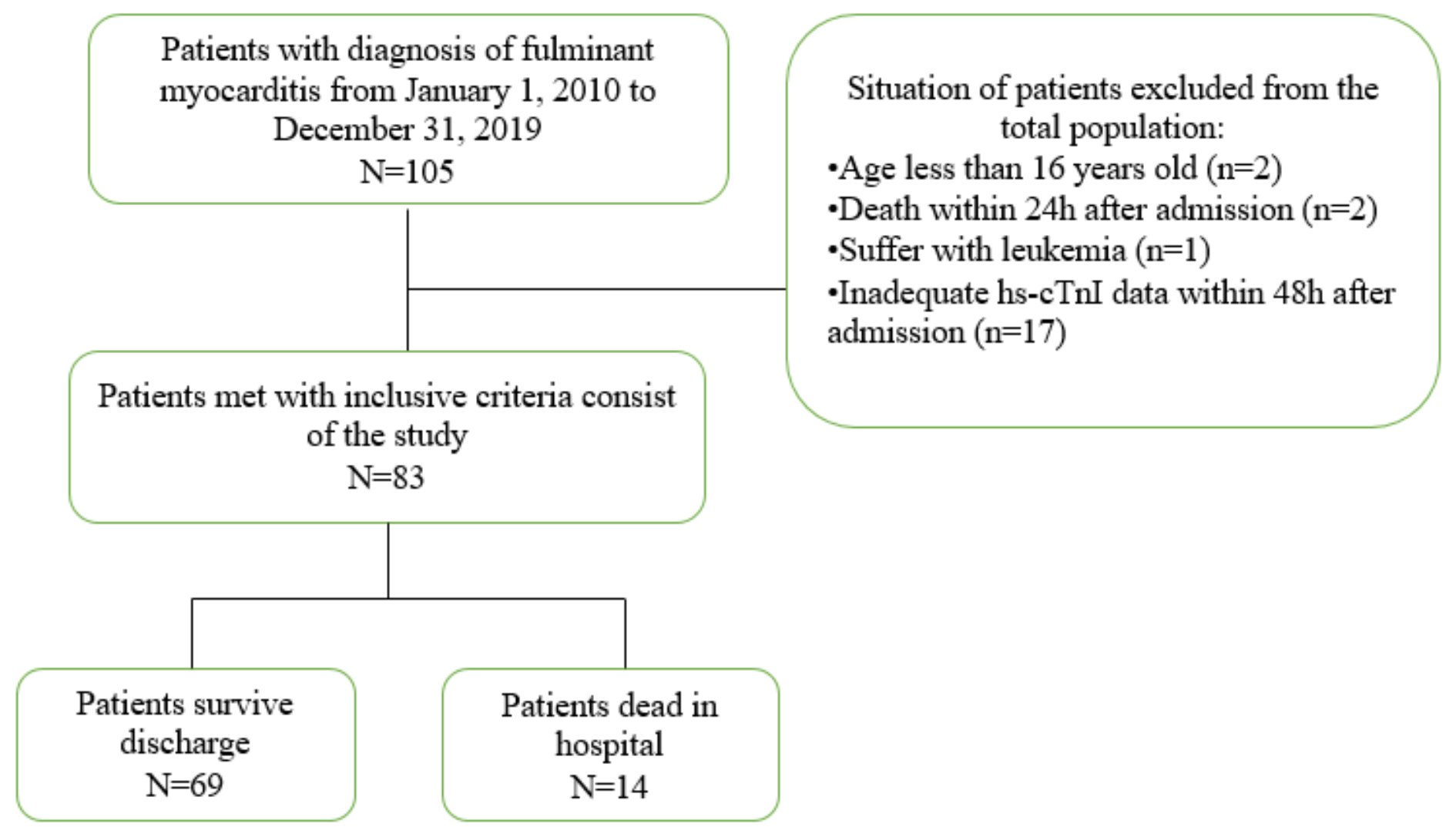

Figure 1

The study process describing enrollment of patient cohort 


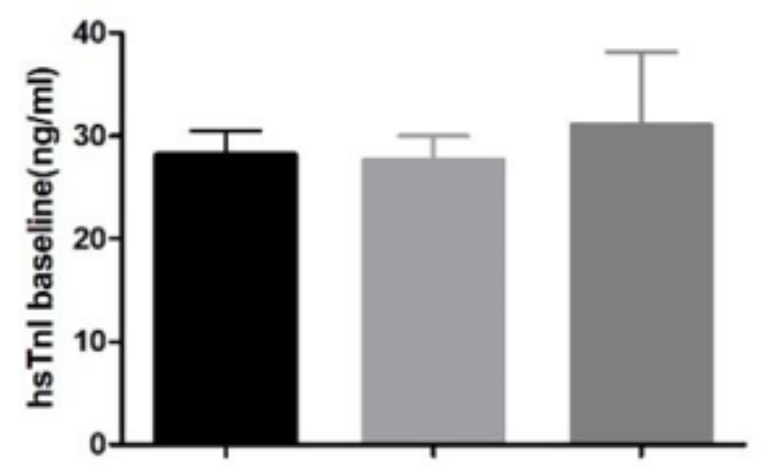

A
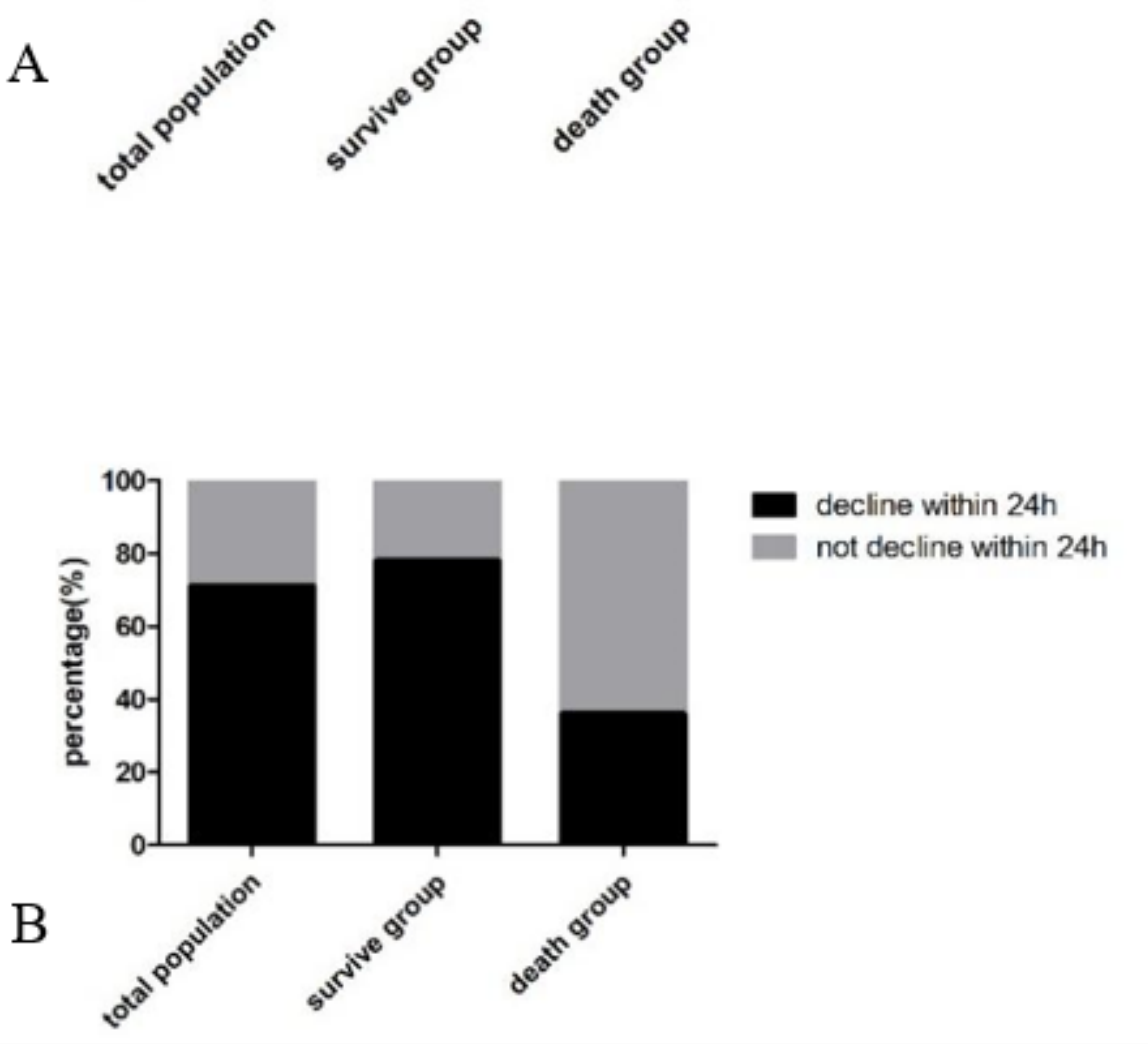

Figure 2

Description of hs-cTnl baseline and tendency. Figure legends: (A): Total population hs-cTnl baseline was the left bar. The survive group and death group was middle and right bar respectively. The average hscTnl value of the two groups was $27.62 \mathrm{ng} / \mathrm{ml}$ and $31.05 \mathrm{ng} / \mathrm{ml}(\mathrm{P}<0.05)$. (B): the proportion of tendency of hs-cTnl change within $24 \mathrm{~h}$. $78 \%$ of Survive group (middle) experienced declined tendency (black) within $24 \mathrm{~h}$ whereas just $36 \%$ of death group (right) showed declined hs-cTnl change within $24 \mathrm{~h}(\mathrm{P}<0.05)$. 

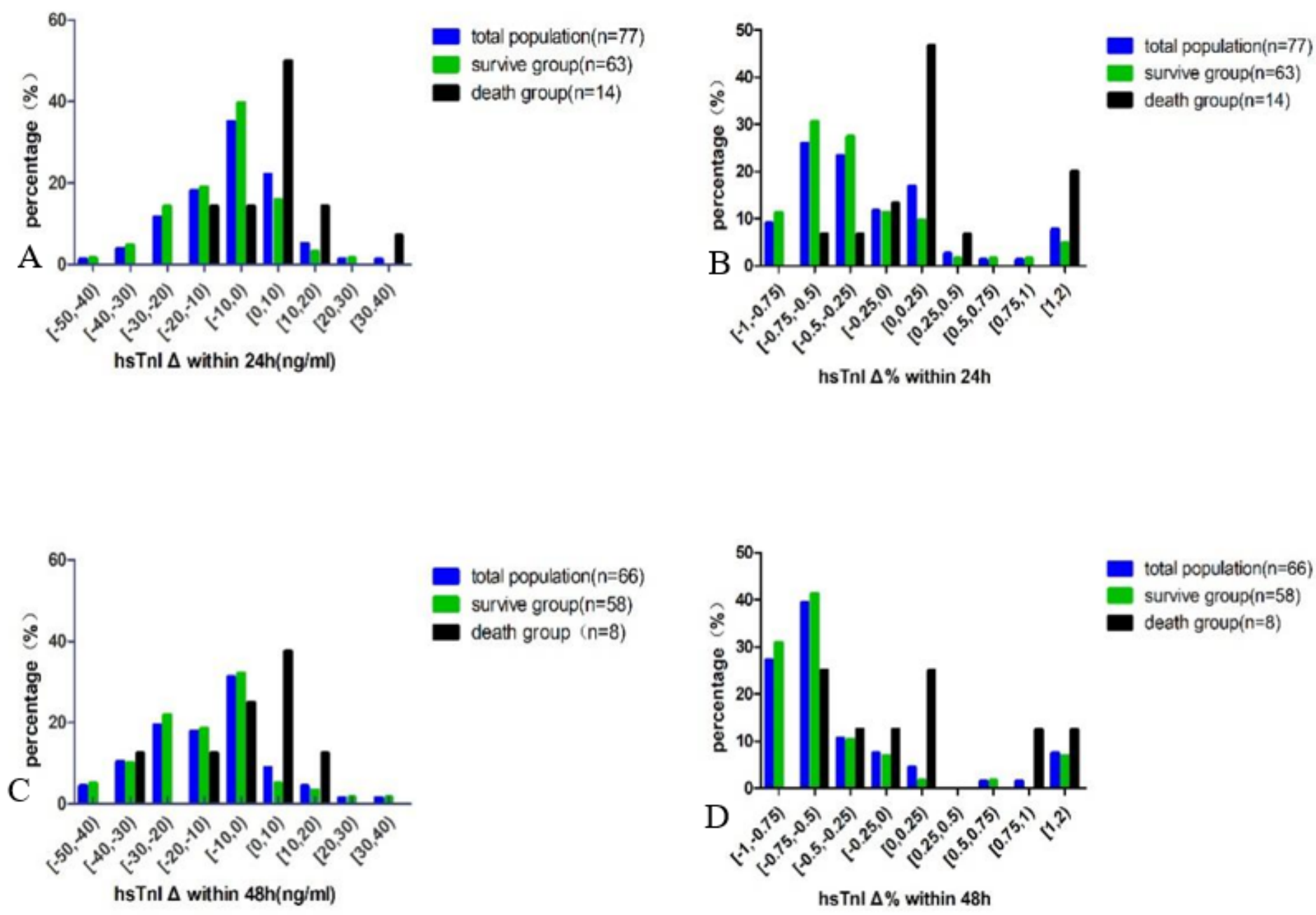

Figure 3

Proportion distribution of hs-cTnl $\Delta$ and hs-cTnl $\Delta \%$ within $24 \mathrm{~h}$ and $48 \mathrm{~h}$ Figure legends: total population (blue), survive group (green), death group (black) were displayed. The range for absolute change within $24 \mathrm{~h}$ and $48 \mathrm{~h}$ of hs-cTnl is between $-50 \mathrm{ng} / \mathrm{ml}$ and $40 \mathrm{ng} / \mathrm{ml}$, with interval as $10 \mathrm{ng} / \mathrm{ml}$. the range for relative change of hs-cTnl is from -1 to 2 , with interval as 0.25 . (A): Absolute change of hs-cTnl within $24 \mathrm{~h}$; (B): relative change of hs-cTnl within 24h; (C): absolute change of hs-cTnl within 48h; (D): relative change of hs-cTnl within $48 \mathrm{~h}$. 


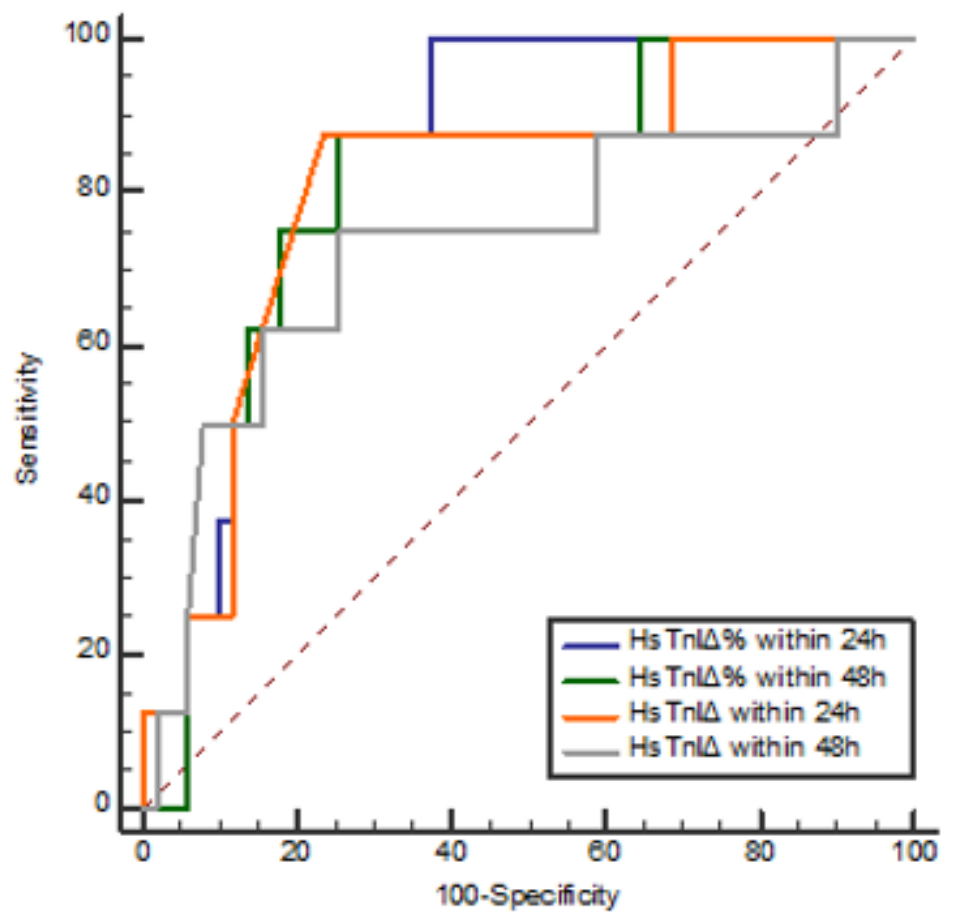

\section{Figure 4}

Diagnostic value of hs-cTnl $\Delta 24 \mathrm{~h}$, hs-cTnl $\Delta 48 \mathrm{~h}$, hs-cTnl $\Delta \% 24 \mathrm{~h}$, hs-cTnl $\Delta \% 48 \mathrm{~h}$ for hospital mortality of patients with fulminant myocarditis. Figure legends: hs-cTnI $\triangle 24 \mathrm{~h}$ (orange):AUC=0.800; hs$\mathrm{cTnl} \Delta 48 \mathrm{~h}$ (grey):AUC=0.711; hs-cTnI $\Delta \% 24 \mathrm{~h}$ (blue):AUC=0.810; hs-cTnl $\Delta \% 48 \mathrm{~h}$ (green):AUC=0.795. 

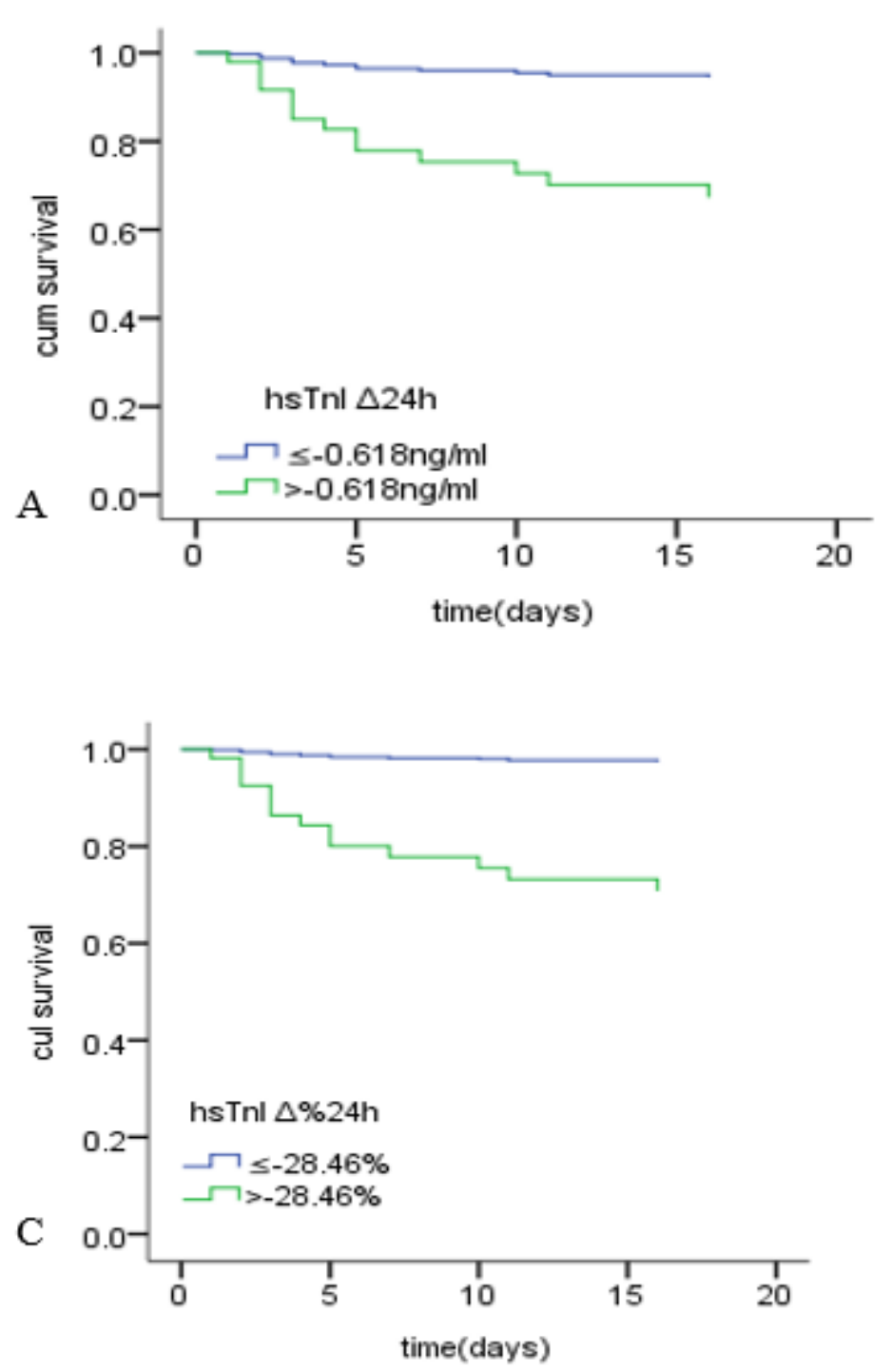
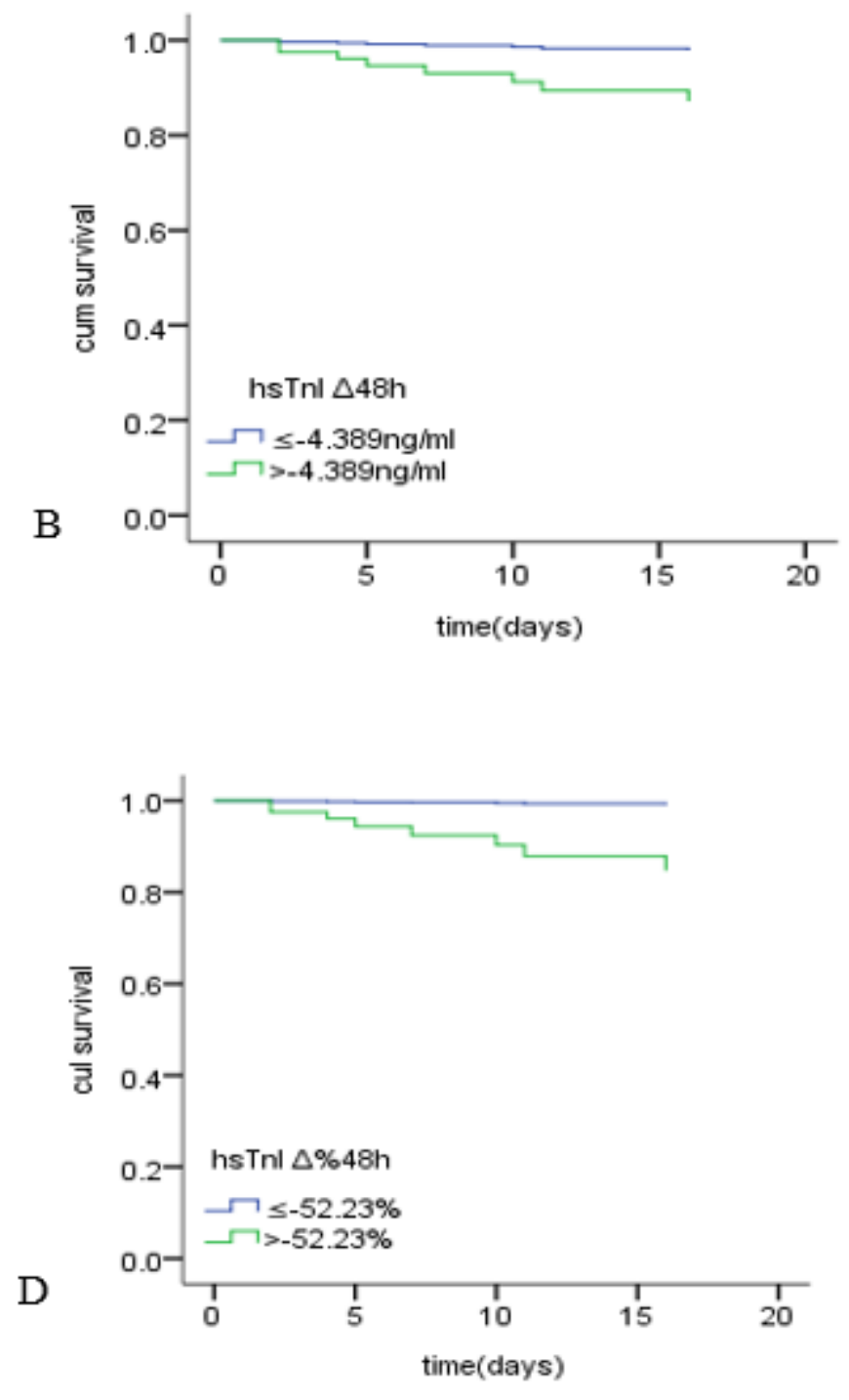

\section{Figure 5}

Cox regression analysis for outcome of FM according to cutoff point Figure legends: A. Cox analysis of hs-cTnI $\Delta 24 \mathrm{~h}$ grouped by cutoff as- $0.618 \mathrm{ng} / \mathrm{ml}$. B. Cox analysis of hs-cTnI $\Delta 48 \mathrm{~h}$ grouped by cutoff as $-4.389 \mathrm{ng} / \mathrm{ml}$. C. Cox analysis of hs-cTnl $\Delta \% 24 \mathrm{~h}$ grouped by cutoff as $-28.46 \%$. D. Cox analysis of hs$\mathrm{cTn} \mid \Delta \% 48 \mathrm{~h}$ grouped by cutoff as $-52.23 \%$. $\mathrm{P}$ value in all models were less than 0.05 . 